Halid, N.A.M.A., et al., Determination of In Vitro Synergy of Ampicilin and Chloramphenicol against Multidrug Resistant Bacillus cereus Species. International Journal of Life Sciences and Biotechnology, 2022.

\title{
Determination of in vitro Synergy of Ampicilin and Chloramphenicol against Multidrug Resistant Bacillus cereus Species
}

\author{
Nur Aina Mardhiah Abdul Halid ${ }^{(i)}$, Kam Kar Yern' ${ }^{1}$ (D), Athena Dana ${ }^{(i)}$, Nor \\ Azimah Mohd Zain 1
}

\section{ABSTRACT}

Nowadays, combination therapy has become one of the most effective clinical practices in treating infections due to the emergence of multi-resistant microorganisms. In this study, minimum inhibitory concentrations (MICs) of six selected antibiotics; ampicillin, gentamicin, tetracycline, rifampicin, chloramphenicol, and ciprofloxacin were screened towards five Bacillus cereus isolates; KS2, E2, F2, F6, and K2W2 isolated from aquaculture sources and river in Kukup, Johor, Malaysia. Determination of MICs on tested antibiotics showed that all B. cereus isolates were resistant towards ampicillin and rifampicin but most sensitive to chloramphenicol, ciprofloxacin, and gentamicin. Apart from that, this investigation also provides the synergistic effect of ampicillin and chloramphenicol against the B. cereus isolates. On contrary, K2W2 resulted as an antagonism while F6 resulted as indifference. In particular, synergy or double therapy of antibiotics may be required to treat multiresistant organisms. Furthermore, the observed synergy between ampicillin and chloramphenicol opens a new window of using bacteriocins and antibiotics in combination therapy of infections.
\end{abstract}

\section{ARTICLE HISTORY}

Received

14 July 2021

Accepted

26 October 2021

\section{KEYWORDS}

Antibiotics, Bacillus cereus, antibiotic resistance, bacteria, synergistic, multidrug resistant

\section{Introduction}

Antibiotics resistant (ABR) or antimicrobial drugs are defined as bacterial intrinsic resistance to certain antibiotics by undergoing mutations of the chromosomal gene as well as horizontal gene transfer [1]. Microorganisms can avoid being killed by antibiotics molecules through sophisticated mechanisms of drug resistance [2], and capable to survive the effect of antibiotic molecules due to the antibiotic's mechanism is no longer inhibiting their growth [3]. This probably happens because of the evolutionary changes in the resistance genes increasing the tolerance of antibiotics and leading to the situation whereas the antibiotic that used to wonder drugs is less functioning to fight off or to combat the infections [4]. The issues of ABR are clinically important as the antibiotics resistance genes can be horizontally transferred to human-associated bacteria and thus contribute to antibiotic resistance proliferation.

\footnotetext{
${ }^{1}$ Department of Biosciences, Faculty of Science, Universiti Tekologi Malaysia, 81310 Johor Bahru, Johor / Malaysia

*Corresponding Autor: Nor Azimah Mohd Zain, e-mail: norazimah@utm.my
} 
Technically, ABR tends to spread from one microorganism to another or between species through the acquisition of a foreign gene or mobile gene via the process of horizontal gene transfer (HGT) [5]. Interestingly, food animals such as cattle, poultry, pigs, and aquaculture are also considered as a big contributor to bacterial resistance. The use of antibiotics in agriculture and aquaculture serves as a great concern in contributing to the emergence of $\mathrm{ABR}$ as they are widely used not only as a source of food but also considered as a source of income [6].

Researchers has found that problem arises on monotherapy to treat infections related to multidrug-resistant (MDR) as they are lesser in efficacy. Some challenges faced in Intensive Care Unit is having difficulty in achieving an adequate treatment for an infection caused by carbapenems producing bacteria and claimed that optimal efficacy was not achieved through monotherapy with agent like polymyxin [7]. Furthermore, the monotherapy antibiotics are not susceptible to certain bacteria particularly for antibiotic-producing bacteria. Some researchers reported that the mortality rates of patient with sepsis or septic shock treated with antimicrobial monotherapy does not decline and it is however increase the mortalility rates [8].

Previously, conventional foresight like antibiotics was once used as the best technique to fight bugs. Combination therapy is generally a plausible method and effective way to fight resistance compare to monotherapy. Combination therapy refers to two antibiotics that are synergistic or combine to produce a stronger effect compares to individual drugs alone [9]. However, there are some risk associated with the combination that are excessive for the antibiotics such as toxicity, costs, resistant strains selection and also superinfections [10]. Hence, the synergistic combination is relatively important for the treatment of MDR bacteria with lower does therapeutic effect.

Therefore, in this study, five Bacillus cereus isolates from the same strain that were isolated from rivers and fishes in Kukup area were selected, as Kukup involving aquaculture fishery activities, which may have become the reservoir for spreading of these bacterial genes to the water. This study was conducted for antibiotic susceptibility testing (AST) including synergistic test via checkerboard method to test for their antibacterial activity towards six selected antibiotics, with the hope that synergy or combination can be applied as an alternative antibacterial in the future. 


\section{Material and Methods}

\section{Materials}

Five Bacillus cereus (KS2, K2W2, F2, F6, and E2) were obtained from previously cultured bacterial isolates in the form of glycerol stock(s) stored at $-80^{\circ} \mathrm{C}$ in Universiti Teknologi Malaysia (UTM). These bacterial isolates were streaked respectively under sterile condition on nutrient agar (Oxoid) prior to performing antibiotic susceptibility test (AST). Next, all of the B. cereus isolates were suspended in Mueller Hinton Broth (MHB) via direct colony suspension method before the determination of minimum inhibitory concentrations (MICs) of different antibiotics were performed. All Thermo Fisher Scientific Oxoid Microbiology media were purchased from VNK Supply \& Services, Johor, Malaysia. Six antibiotics with certificates of authentication were used including ampicillin, gentamicin, tetracycline, rifampicin, chloramphenicol, and ciprofloxacin and were purchased from Bio-Basic, Canada.

\section{Sampling site profile}

A series of serial dilution was prepared and the diluted sample was spread on the nutrient agar followed by bacterial incubation at $37^{\circ} \mathrm{C}$ for 24 hours. The isolated bacterial was characterized based on their morphological characteristics and Gram staining was performed [11]. The morphological characterisation and Gram staining were served as the preliminary data for phenotypic bacterial identification.

\section{Antibiotic susceptibility testing}

Aquaculture sources (fish) and water samples were collected from Kukup $\left(1^{\circ} 19^{\prime} 40.0^{\circ} \mathrm{N}\right.$, $103^{\circ} 26^{\prime} 22.9^{\circ} \mathrm{E}$ ). Water samples were collected from three points by using the dip sampling method and three fish samples were collected in each location. Fish samples were transported at $4{ }^{\circ} \mathrm{C}$ to the laboratory and dissected within $4 \mathrm{~h}$ after collection according to the standard operating protocol [12]. The sample processing was performed on the fish samples where $10 \mathrm{~g}$ of internal guts and digestive tracts were ground with $10 \mathrm{ml}$ sterile distilled water and $1 \mathrm{ml}$ aliquot volume was measured and homogenized in $9 \mathrm{ml}$ of sterile distilled water to give a 1:10 dilution [13]. The collected fish sample is Lates Calcarifer.

\section{Genotypic Identification of Bacterial Isolates via 16S rRNA Sequencing}

The bacterial DNA was extracted from overnight culture by using the simple boiling method $[13,14]$. The extracted DNA was used to perform PCR amplification with GOTAQ ${ }^{\circledR}$ Promega Green Master Mix and $0.5 \mu \mathrm{M}$ forward primer (fD1, 5'AGAGTTTGATCATGGCTCAG-'3) and reverse primer (rP1, 5'ACGGTTACCTTGTTACGACTT-'3) [15]. The forward and reverse primer were 
manufactured by Integrated DNA Technologies (IDT), Malaysia. The PCR mixtures ( $25 \mu \mathrm{L})$ method started with the preheating step for activation of Taq polymerase at $95{ }^{\circ} \mathrm{C}$ for 3 mins, followed by 30 cycles of denaturation at $95{ }^{\circ} \mathrm{C}$ for $40 \mathrm{sec}$, annealing process at $55^{\circ} \mathrm{C}$ for 30 sec and extension at $72{ }^{\circ} \mathrm{C}$ for $1.5 \mathrm{~min}$, with a final extension at $72{ }^{\circ} \mathrm{C}$ for $5 \mathrm{~min}$ [16]. The PCR amplicons were electrophoresed in $1 \% \mathrm{w} / \mathrm{v}$ agarose gels with a molecular size marker ( $1 \mathrm{~kb}$ GeneRuler) at $85 \mathrm{~V}$ for $45 \mathrm{~min}$. The gel was stained with ethidium bromide for 5 minutes, rinsed, and viewed under ultraviolet light illumination. The resulting band size of the amplicons was $\sim 1500 \mathrm{bp}$.

\section{DNA Sequencing and Phylogenetic Analysis}

The unpurified PCR products were outsourced to Apical Scientific Sdn. Bhd. (Selangor, Malaysia) for sequencing. The resulting DNA sequences were analyzed by using the Bioedit software (version 7.2.5.0) to obtain the complementary sequences. The sequences of the PCR products obtained were analyzed with nucleotide Basic Local Alignment Search Tool (BLASTn) and by multiple sequence alignment using the ClustalW program provided by the National Center of Biology Information (NCBI) [17]. The phylogenetic analysis was carried out by using MEGA 7 software (version 10.1.1) to generate the phylogenetic tree and the relationship between the isolates of the most abundant bacterial species in each site. The multiple sequence alignments were performed with ClustalW [18] and the phylogenetic tree for each site was constructed by MEGA 7 with 1000 bootstraps [19].

\section{Antibiotic Stock Solution Preparation}

Stock solution for six tested antibiotics includes gentamicin, ampicillin, tetracycline, chloramphenicol, ciprofloxacin, and rifampicin with potency were suspended in $10 \mathrm{~mL}$ suitable solvent or diluent as shown in Table 1. The stock solutions were then stored in the refrigerator at $4{ }^{\circ} \mathrm{C}$ for further analysis.

Table 1 Solvent for six different antibiotics include ampicillin, gentamicin, tetracycline, rifampicin, chloramphenicol, and ciprofloxacin stock solution

\begin{tabular}{|c|c|c|c|}
\hline Antibiotic & Solvent/diluent & Storage & $\begin{array}{c}\text { Brand } \\
\text { Name/Manufacturer }\end{array}$ \\
\hline Ampicillin & Sterile distilled water & $4{ }^{\circ} \mathrm{C}$ & Bio Basic, Canada \\
\hline Gentamicin & Sterile distilled water & $4{ }^{\circ} \mathrm{C}$ & Bio Basic, Canada \\
\hline Tetracycline & $70 \%$ Ethanol & $-20^{\circ} \mathrm{C}$ & Bio Basic, Canada \\
\hline Rifampicin & Absolute Methanol & $4{ }^{\circ} \mathrm{C}$ & Bio Basic, Canada \\
\hline Chloramphenicol & Absolute Ethanol & $4{ }^{\circ} \mathrm{C}$ & Bio Basic, Canada \\
\hline Ciprofloxacin & Sterile distilled water & $25^{\circ} \mathrm{C}$ & Bio Basic, Canada \\
\hline
\end{tabular}




\section{Determination of Minimal Inhibitory Concentrations (MICs)}

An inoculum equal to a 0.5 McFarland turbidity standard was prepared from each $B$. cereus isolate, and $10 \mu \mathrm{l}$ of the suspension was inoculated onto Mueller-Hinton agar plates. The MICs of the tested antibiotics were determined by the broth microdilution method as described [20]. The MICs of ampicillin, ciprofloxacin, rifampicin, chloramphenicol, gentamicin, and tetracycline, for the $5 \mathrm{~B}$. cereus isolates were determined by using 96 well microtiter plate (Eppendorf). Next, $2 \mathrm{X}$ higher stock is prepared for each antibiotic. The stock solutions were prepared by using the formula [21]:

$$
\frac{1000}{P} \times V \times C=W
$$

where $\mathrm{P}=$ potency given by manufacturer $(\mu \mathrm{g} / \mathrm{mg}), \mathrm{V}=$ volume required $(\mathrm{ml}), \mathrm{C}=$ final solution concentration (multiples of 1000) ( $\mathrm{mg} / \mathrm{l}$ ), and $\mathrm{W}=$ weight of antibiotic $(\mathrm{mg})$ to be dissolved in volume $\mathrm{V}(\mathrm{ml})$. Then, $50 \mu \mathrm{MHB}$ was added into each well include positive and negative control well. A total volume of 50ul of $2 \mathrm{X}$ higher of the final concentration of antibiotic is added into column 1. Two-fold serial dilution was performed by transferring 50ul from column 1 to column 10. The process was repeated for each column and each row for each antibiotic. Next, $10 \mu 1$ of bacterial suspension is added into the well except for Column 12 (sterility control). After 24 hours of incubation, $5 \mathrm{ul}$ of resazurin assay $(6.75 \mathrm{mg}$ ) were added to indicate the viability of the cell and the result for MICs were observed after 4 hours of incubation with resazurin. Columns with no colour change (resazurin remained as blue colour) will be taken as the MIC value [22].

\section{Synergistic Testing (Checkerboard Assay)}

The Checkerboard assay was used to evaluate synergism among ampicillin and chloramphenicol against the B. cereus. Broth microdilution assay was performed on a 96microtitre plate. Each isolate was tested against double combinations of antibiotics. A double combination including ampicillin and chloramphenicol were chosen against B. cereus. A single (MIC test for chloramphenicol and ampicillin) and double combinations of antibiotics against a single isolate of $B$. cereus were performed on 96-well plates as described by Elshikh et al. (2016) with modifications [22]. Briefly, columns 1 and 2 were used for the determination of MICs for each antibiotic alone (MIC test for chloramphenicol and ampicillin). Two times higher of the final concentration of antibiotics was added and two-fold serial dilution were performed from row A to row $\mathrm{H}$ (columns 1 and 2). Column 11 and 
column 12 were acted as a growth control and sterility control, respectively. Columns 3 to 10 were used for double antibiotics combination for chloramphenicol and ampicillin as described by El-Azizi (2016) with modifications [20]. Briefly, each well was filled with 50 $\mu$ MHB. Fifty microliters of the ampicillin at $4 \mathrm{x}$ higher tested were added into column 3 (A3 to H3) and two-fold serial dilution was performed for each row. The remaining $50 \mu 1$ portions were discarded from each last row. Then, $50 \mu \mathrm{l}$ of the chloramphenicol at $2 \mathrm{x}$ higher tested was added into row A (A3 to A10) and a two-fold serial dilution was performed for each column (A to $\mathrm{H}$ ). The remaining $50 \mu \mathrm{l}$ portions were discarded from every last column. Finally, a volume of 10ul bacterial suspensions was added into each well except for column 12. All plates were incubated at $37^{\circ} \mathrm{C}$ for 24 hours. After 24 hours of incubation, $5 \mathrm{ul}$ of resazurin assay $(6.75 \mathrm{mg})$ were added to indicate the viability of the cell and the result for MICs for double antibiotic combination were observed after 4 hours incubation with resazurin. Columns with no colour change (resazurin remained as blue colour) will be taken as the MIC value [22]. The calculation for the Fractional inhibitory concentration index (FICI) was used to interpret the synergistic result [23].

$$
\text { FICI }=\frac{\text { MICs of drug A in combination }}{\text { MICs of drug A alone }}+\frac{\text { MICs of drug B in combination }}{\text { MICs of drug B alone }}
$$

\section{Results and Discussion}

\section{Bacteria Identification}

Five Bacillus species isolates were successfully isolated from fish and water samples from Kukup; KS2, F2, E2, F6, and K2W2. All of the isolates yielded amplicons with the expected band size of $1.5 \mathrm{~kb}$ with good intensity and brightness in gel analysis. High identity percentages (92-100\%) to the B. cereus strain (accession number: NR_074540.1) and low Evalues were observed in the BLASTn analysis, which strongly suggests the accuracy and reliability of the identification results [24]. The Bacillus spp. occurs in the highest percentage in the fish samples as they are commonly used as probiotics in aquaculture [25]. All Bacillus isolates were identified as the same strain, which is Bacillus cereus strain ATCC 14579 as showed in Table 2. All the sequences of B. cereus isolates obtained were deposited into the NCBI gene bank and the sequences accession number were shown in Table 2. 
Table 2 List of 16s rRNA sequences of $B$. cereus and the accession numbers obtained

\begin{tabular}{|c|l|c|c|c|}
\hline Isolates & \multicolumn{1}{|c|}{ Species } & Identity & Accession & $\begin{array}{c}\text { Sequence ID } \\
\text { deposited in the } \\
\text { NCBI gene bank }\end{array}$ \\
\hline E2 & $\begin{array}{l}\text { Bacillus cereus strain ATCC 14579 16S } \\
\text { ribosomal RNA (rrnA), partial sequence }\end{array}$ & $100 \%$ & NR_074540.1 & MK294257 \\
\hline F2 & $\begin{array}{l}\text { Bacillus cereus strain ATCC 14579 16S } \\
\text { ribosomal RNA (rrnA), partial sequence }\end{array}$ & $100 \%$ & NR_074540.1 & MK294260 \\
\hline F6 & $\begin{array}{l}\text { Bacillus cereus strain ATCC 14579 16S } \\
\text { ribosomal RNA (rrnA), partial sequence }\end{array}$ & $100 \%$ & NR_074540.1 & MK294264 \\
\hline K2W2 & $\begin{array}{l}\text { Bacillus cereus strain ATCC 14579 16S } \\
\text { ribosomal RNA (rrnA), partial sequence }\end{array}$ & $\begin{array}{l}\text { Bacillus cereus strain ATCC 14579 16S } \\
\text { ribosomal RNA (rrnA), partial sequence }\end{array}$ & NR_074540.1 & MK294267 \\
\hline KS2 & NR_074540.1 & MK294268 \\
\hline
\end{tabular}

\section{Minimal inhibitory concentration (MIC)}

The resistant patterns of six antibiotics for five B. cereus isolates (KS2, F2, E2, F6, and K2W2) were determined and the results are shown in Table 3. Generally, every B. cereus isolate shows different MICs towards each antibiotic. Study revealed that all B. cereus that were isolated from different sources, showed the $100 \%$ resistance to ampicillin. Interestingly, Investigation on the prevalence and antimicrobial susceptibility pattern of bacteria isolated from water and fish species Rastrineobola argentea and Oreochromis niloticusi and revealed that both fish and river showed that all the isolates were resistant to beta-lactam antibiotic (ampicillin) [26].

Previous study also reported that B. cereus isolates showed resistance to beta-lactam antibiotics [27]. Therefore, B. cereus generally produces beta-lactamase and is uniformly resistant to beta-lactam antibiotics. In a previous study by Sukmarini et al. (2014), they stated that most Bacillus spp. were susceptible to non $\beta$-lactam antibiotics [28]. In our study, all $B$. cereus isolates can be concluded to produce $\beta$-lactamase enzyme since they were all resistant towards beta-lactam antibiotics. The mechanism of beta-lactam degradation can be seen through the enzymatic inactivation. In this group, bacteria producing beta-lactamase enzymes synthesized beta-lactam antibiotic therefore keep increase in number which is inactivates enzymes include chloramphenicol and erythromycin [29].

From this study, it can be seen that all Bacillus spp. were resistant to rifampicin (Table 3). According to Soren et al. (2015), rifampicin antibiotics cannot be considered as a standard treatment due to there is no breakpoint for the resistance [30]. Rifampicin inhibits bacterial 
DNA-dependent RNA synthesis by inhibiting bacterial DNA-dependent for instance in Grampositive bacteria and mycobacteria. Rifampicin acts on bacterial RNA polymerase by adhering to the pocket of bacterial RNA polymerase $\beta$ subunit 29 within DNA or RNA, hence it could block the expression of bacterial genes. However, rifampicin antibiotics cannot work alone due to $\beta$ subunit of bacterial RNA polymerase (RNAP) easily get mutated [31]. In fact, instead of monotherapy combination therapy is used to stop the development of resistance and to shorten the length of treatment.

According to Lahiri et al., (2016), most resistance towards rifampicin are acquired through missense mutations that take place in the rifampicin binding site on the RNA polymerase subunit that is responsible for determination of rifampicin resistance (encoded by rpoB gene which is the 81 base pair region) [32]. This statement is also supported by Vogler et al., (2002) where beta subunit of RNA polymerase gene mutation are commonly pointed as the cause for rifampicin resistance [33]. The result in this study corresponding with their finding in which the resistance among Bacillus spp. can be particularly seen towards rifampicin antibiotics. Similarly, findings by Dabbs et al., (1995) presented 20 Bacillus strain that were able to inactivate rifampicin antibiotics which including B. Cereus [34]. Besides, finding by Park et al., (2020) shows that particular strain B. cereus was highly resistant towards rifampicin [27].

Besides that, E2 and F6 show high resistance towards tetracycline. On contrary, F2 and $\mathrm{K} 2 \mathrm{~W} 2$ show the isolates were sensitive to the tetracycline. However, only one isolate from Table 3 shows indifference towards the tetracycline. Different sources show different patterns of antimicrobial susceptibility. Tetracycline antibiotics are extensively used for human medicine and aquaculture. Therefore, the resistance was higher according to E2 and F6. This may be due to this type of Bacillus spp. coming from the aquatic environment. Our findings are in agreement with some study which shows that the increase of resistance take place along the rivers subject to urban or agricultural activities that end ups in the aquatic environment that cause the presence of tetracycline and tetracycline resistant bacteria that originate from wastewater and source of agricultural [35]. This outcome also corresponds with Shah et al., (2012) where only isolates from Tanzania fish farming consist of tetracycline resistance genes which are $\operatorname{tet} A(\mathrm{~A})$ and $\operatorname{tet} A(\mathrm{G})$ are found, in which there are no history of antibiotic usage found in the location [36]. However, the mechanism that responsible for the high densities of the resistant bacteria in aquatic environment remains unclear. The main mechanism responsible for the emergence of tetracycline-resistant is efflux energy-dependent, protection of the ribosomal of bacteria, and enzymatic inactivation of the tetracycline molecule. Notably, 
Bacillus spp. carry either gene tet( $L)$ or tet( $K)$ on the plasmid and/ or on their chromosome. Besides, these genes are mobilized through the conjugative plasmid and distribute within populations other than these genes are involved to encode the efflux protein which pump the tetracycline and doxycycline out from the cells [37].

Furthermore, all B. cereus isolates were sensitive to ciprofloxacin, chloramphenicol, and gentamicin. Similarly, Weber et al., (1988) also explained that most B. cereus isolates were susceptible to chloramphenicol, ciprofloxacin, and tetracycline [38]. The outcome also compatible with Naas et al., (2018) reported that B. cereus mostly sensitive to gentamicin, ciprofloxacin, and also chloramphenicol [39]. Chloramphenicol is a well-known drug that plays a major role as therapeutic agents. Consistent with other studies, our findings also reveal that the Bacillus cereus from different sources is most susceptible to chloramphenicol. This may be due to the Bacillus cereus provides a mode of action which chloramphenicol causes a bacteriostatic effect by binding to the $50 \mathrm{~S}$ ribosomal subunit and inhibiting the transpeptidation step in protein synthesis [40].

In conclusion, all the isolates show different antimicrobial sensitivity on the tested antibiotics including ampicillin, gentamicin, tetracycline, rifampicin, chloramphenicol, and ciprofloxacin. In our study, all B. cereus were resistant to the ampicillin and rifampicin antibiotics. On contrary, all B. cereus were sensitive to gentamicin, chloramphenicol, and ciprofloxacin. The variation of antimicrobial sensitivity prevalent depends on the difference in concentration of antibiotic agents, differences source of isolates, drug resistance transfer, and widespread misuse of antibiotic in field [41].

Table 3 Determination of MIC Tested Antibiotics Against Bacillus cereus Isolates

\begin{tabular}{|c|c|c|c|c|c|c|c|}
\hline \multirow[t]{2}{*}{ Isolates } & \multirow{2}{*}{$\begin{array}{c}\text { Antimicrobial } \\
\text { agents }\end{array}$} & \multirow{2}{*}{$\begin{array}{l}\text { MIC range } \\
(\mu \mathrm{g} / \mathrm{mL})\end{array}$} & \multicolumn{3}{|c|}{ MIC standard from CLSI $(\mu \mathrm{g} / \mathrm{mL})$} & \multirow{2}{*}{$\begin{array}{c}\mathrm{MIC} \\
(\mu \mathrm{g} / \mathrm{mL})\end{array}$} & \multirow[t]{2}{*}{ Interpretation } \\
\hline & & & Susceptible & Intermediate & Resistance & & \\
\hline \multirow[t]{6}{*}{ KS2 } & GN & $\begin{array}{c}0.03125 \text { to } \\
16\end{array}$ & $\leq 4$ & 8 & $\geq 16$ & 0.5 & $\mathrm{~S}$ \\
\hline & TET & 0.25 to 128 & $\leq 4$ & 8 & $\geq 16$ & 8 & I \\
\hline & RIF & $\begin{array}{c}0.03125 \text { to } \\
16 \\
\end{array}$ & N.A. & N.A. & N.A. & 0.125 & $\mathrm{R}$ \\
\hline & AMP & 4 to 2084 & $\leq 8$ & 16 & $\geq 32$ & 1024 & $\mathrm{R}$ \\
\hline & $\mathrm{CHL}$ & 0.25 to 128 & $\leq 8$ & 16 & $\geq 32$ & 4 & $\mathrm{~S}$ \\
\hline & CIP & $\begin{array}{c}0.03125 \text { to } \\
16 \\
\end{array}$ & $\leq 1$ & 2 & $\geq 4$ & 0.25 & $\mathrm{~S}$ \\
\hline \multirow[t]{3}{*}{$\mathrm{F} 2$} & GN & $\begin{array}{c}0.03125 \text { to } \\
16\end{array}$ & $\leq 4$ & 8 & $\geq 16$ & 0.025 & $\mathrm{~S}$ \\
\hline & TET & 0.25 to 128 & N.A. & 8 & $\geq 16$ & 2 & $\mathrm{~S}$ \\
\hline & RIF & $\begin{array}{c}0.03125 \text { to } \\
16\end{array}$ & N.A. & N.A. & N.A. & $<0.03$ & $\mathrm{R}$ \\
\hline
\end{tabular}




\begin{tabular}{|c|c|c|c|c|c|c|c|}
\hline & AMP & 4 to 2084 & $\leq 8$ & 16 & $\geq 32$ & 128 & $\mathrm{R}$ \\
\hline & CHL & 0.25 to 128 & $\leq 8$ & 16 & $\geq 32$ & 2 & S \\
\hline & CIP & $\begin{array}{c}0.03125 \text { to } \\
16\end{array}$ & $\leq 1$ & 2 & $\geq 4$ & 0.0625 & S \\
\hline \multirow[t]{6}{*}{ E2 } & GN & $\begin{array}{c}0.03125 \text { to } \\
16\end{array}$ & $\leq 4$ & 8 & $\geq 16$ & 0.5 & S \\
\hline & TET & 0.25 to 128 & $\leq 4$ & 8 & $\geq 16$ & 32 & $\bar{R}$ \\
\hline & RIF & $\begin{array}{c}0.03125 \text { to } \\
16\end{array}$ & N.A. & N.A. & N.A. & 2 & $\mathrm{R}$ \\
\hline & AMP & 4 to 2084 & $\leq 8$ & 16 & $\geq 32$ & 2084 & $\mathrm{R}$ \\
\hline & CHL & 0.25 to 128 & $\leq 8$ & 16 & $\geq 32$ & 4 & S \\
\hline & CIP & $\begin{array}{c}0.03125 \text { to } \\
16\end{array}$ & $\leq 1$ & 2 & $\geq 4$ & 1 & S \\
\hline \multirow[t]{6}{*}{ F6 } & GN & $\begin{array}{c}0.03125 \text { to } \\
16\end{array}$ & $\leq 4$ & 8 & $\geq 16$ & 0.0625 & S \\
\hline & TET & 0.25 to 128 & $\leq 4$ & 8 & $\geq 16$ & 32 & $\bar{R}$ \\
\hline & RIF & $\begin{array}{c}0.03125 \text { to } \\
16\end{array}$ & N.A. & N.A. & N.A. & 0.125 & $\mathrm{R}$ \\
\hline & AMP & 4 to 2084 & $\leq 8$ & 16 & $\geq 32$ & 2084 & $\mathrm{R}$ \\
\hline & CHL & 0.25 to 128 & $\leq 8$ & 16 & $\geq 32$ & 2 & S \\
\hline & CIP & $\begin{array}{c}0.03125 \text { to } \\
16\end{array}$ & $\leq 1$ & 2 & $\geq 4$ & 0.5 & $\mathrm{~S}$ \\
\hline \multirow[t]{6}{*}{ K2W2 } & GN & $\begin{array}{c}0.03125 \text { to } \\
16\end{array}$ & $\leq 4$ & 8 & $\geq 16$ & 0.125 & S \\
\hline & TET & $\begin{array}{c}0.015625 \text { to } \\
8\end{array}$ & $\leq 4$ & 8 & $\geq 16$ & 0.125 & S \\
\hline & RIF & 0.0039 to 2 & N.A. & N.A. & N.A. & 0.25 & $\bar{R}$ \\
\hline & AMP & $\begin{array}{c}0.03125 \text { to } \\
16\end{array}$ & $\leq 8$ & 16 & $\geq 32$ & 2 & S \\
\hline & CHL & $\begin{array}{c}0.015625 \text { to } \\
8\end{array}$ & $\leq 8$ & 16 & $\geq 32$ & 0.25 & S \\
\hline & CIP & $\begin{array}{c}0.03125 \text { to } \\
16\end{array}$ & $\leq 1$ & 2 & $\geq 4$ & 0.0625 & $S$ \\
\hline
\end{tabular}

\section{Fractional inhibitory concentration index (FICI)}

Based on Table 4, KS2, F2, and E2 showed synergistic effects with FICI $(\leq 0.5)$ on the antibiotic combination tested (ampicillin + chloramphenicol). There is no previous study shows the synergistic effect for the combination of ampicillin and chloramphenicol for $B$. cereus spp and this could be a new finding in which further study will be needed. On contrary, B. cereus isolates $\mathrm{K} 2 \mathrm{~W} 2$ shows antagonism with FICI $(\geq 2.0)$ when introduced with ampicillin and chloramphenicol. This is strongly supported by Manten and Terra (1964), which reported that antagonism was obtained when chloramphenicol and $\beta$ lactam group antibiotics (penicillin) were applied [42]. Despite chloramphenicol and penicillin are not from the same group of antibiotics, yet the synergistic effect still cannot be obtained since the chloramphenicol is a bacteriostatic antibiotic (reversible stoppage) may partly or completely destroy the bactericidal actions of penicillin [42]. Back in 1981, Weeks et al., conducted a 
clinical study which uses double therapy antibiotics such as bactericidal and bacteriostatic, resulted in poor outcome compared to the monotherapy bactericidal [43]. Notably, B. cereus F6 shows indifference (not additive or synergistic) results when introduced with ampicillin and chloramphenicol. Similarly, this outcome is compatible with Cole et al., (1979) saying that there is no antagonistic effect between chloramphenicol and ampicillin combination also, indifferent (not additive or synergistic) effects when ampicillin and chloramphenicol being introduced [44]. Table 5 shows the FICI interpretation range that were used in this study.

Table 4 Synergistic Effect of Ampicillin and Chloramphenicol Combination Against Five $B$. Cereus Isolates

\begin{tabular}{|c|c|c|c|c|c|c|}
\hline \multirow{2}{*}{ Isolates } & \multicolumn{2}{|c|}{$\begin{array}{c}\text { MIC Antibiotic A (CHL) } \\
(\mu \mathrm{g} / \mathrm{mL})\end{array}$} & \multicolumn{2}{c|}{$\begin{array}{c}\text { MIC Antibiotic B (AMP) } \\
(\mu \mathrm{g} / \mathrm{mL})\end{array}$} & FICI & Interpretation \\
\cline { 2 - 5 } & Alone & In combination & Alone & In Combination & & \\
\hline KS2 & 2 & 1 & 2048 & 256 & 0.625 & Synergy \\
\hline F2 & 0.5 & $<0.0625$ & 16 & $<4$ & 0.375 & Synergy \\
\hline E2 & 4 & $<0.125$ & 2048 & $<64$ & 0.0625 & Synergy \\
\hline F6 & 1 & 0.5 & 128 & 128 & 1.5 & Indifference \\
\hline K2W2 & 0.03125 & $<0.0078125$ & 0.25 & $<0.0625$ & 2.75 & Antagonism \\
\hline
\end{tabular}

Table 5 FICI interpretation range use in this study

\begin{tabular}{|c|c|}
\hline \multicolumn{2}{|c|}{ FICI Interpretation Range } \\
\hline FICI $\leq 0.5$ & Synergy \\
\hline $0.5<\mathrm{FICI} \leq 1.0$ & additive \\
\hline $1.0<\mathrm{FICI} \leq 2.0$ & Indifference \\
\hline FICI $\geq 2.0$ & Antagonism \\
\hline
\end{tabular}

\section{Conclusion}

All of the B. cereus isolates (KS2, E2, F2, F6, and K2W2) showed difference antimicrobial sensitivity towards the tested antibiotics; ampicillin, gentamicin, tetracycline, rifampicin, chloramphenicol, and ciprofloxacin. All B. cereus isolates were resistant to the ampicillin and rifampicin. On contrary, all B. cereus were sensitive to the gentamicin, chloramphenicol, and ciprofloxacin. The variation of antimicrobial sensitivity prevalent depends on difference in concentration of antibiotic agents, differences source of isolates, drug resistance transfer, and wide spread misuse of antibiotic in field. Three isolates (KS2, F2, and E2) showed synergistic 
effects toward the antibiotic combination. More studies are required to facilitate the understanding of results obtained including the mechanism and the potential of these combination therapy as this could serve as preliminary data and can be useful to support therapeutic decisions clinically in future.

\begin{abstract}
Abbreviations
ABR: Antibiotic Resisrant; HGT: Horizontal gene transfer, MDR: Multidrug-resistant; ICU: Intensive care unit; AST: Antibiotic susceptibility testing; UTM: Universiti Teknologi Malaysiat; NA: Nutrient Agar; MHB: Mueller Hinton Broth; MICs: Basic Local Alignment Search Tool; NCBI: National Cancer of Biology Information; CLSI: Clinical and Laboratory Standards Institute; FICI: Fractional inhibitory concentration index; RNAP: Bacterial RNA polymerase

Acknowledgements

We sincerely thank the staff and administration of the Universiti Teknologi Malaysia for their assistance and support in this study.

Funding

The authors are grateful to Universiti Teknologi Malaysia for Geran Universiti Penyelidikan (GUP) sub vote 17H74 and UTMShine Grant sub vote 04G97. The financial support from the Ministry of Higher Education (MOHE) is also greatly acknowledged.

Availability of data and material
\end{abstract}

Please contact the corresponding author for any data request.

\title{
References
}

1. Blair, J.M.A., et al., Molecular mechanisms of antibiotic resistance. Nature Reviews Microbiology, 2015. 13(1): p. 42-51.

2. Li, B. and J.W. Thomas, Bacteria antibiotic resistance: New challenges and opportunities for implantassociated orthopedic infections. Journal of Orthopaedic Research, 2018. 36(1): p. 22-32.

3. Munita, J.M. and C.A. Arias, Mechanisms of antibiotic resistance. Microbiology Spectrum, 2016. 4(2): 10.1128/microbiolspec.VMBF-0016-2015.

4. Abebe, E., B. Tegegne, and S. Tibebu, A review on molecular mechanisms of bacterial resistance to antibiotics. European Journal of Applied Sciences, 2016. 8(5): p. 301-310.

5. Fletcher, S., Understanding the contribution of environmental factors in the spread of antimicrobial resistance. Environmental Health and Preventive Medicine, 2015. 20(4): p. 243-252.

6. Economou, V., and P. Gousia, Agriculture and food animals as a source of antimicrobial-resistant bacteria. Infection and Drug Resistance, 2015. 8: p. 49.

7. Karam, G., et al., Antibiotic strategies in the era of multidrug resistance. Critical Care, 2016. 20(1): p. $1-9$.

8. Ripa, M., et al., Influence of empirical double-active combination antimicrobial therapy compared with active monotherapy on mortality in patients with septic shock: a propensity score-adjusted and matched analysis. Journal of Antimicrobial Chemotherapy, 2017. 72(12): p. 3443-3452.

9. Pena-Miller, R., et al., When the most potent combination of antibiotics selects for the greatest bacterial load: the smile-frown transition. PLoS biology, 2013. 11(4): e1001540.

10. Tängdén, T., Combination antibiotic therapy for multidrug-resistant Gram-negative bacteria. Upsala Journal of Medical Sciences, 2014. 119(2): p. 149-153.

11. Junior, J.C.R., et al., Efficiency of boiling and four other methods for genomic DNA extraction of deteriorating spore-forming bacteria from milk. Semina: Ciências Agrárias, 2016. 37(5): p. 3069-3078.

12. Rainwater, F.H., and L.L. Thatcher, Water Supply Paper, in Methods for collection and analysis of water samples, F.H. Rainwater and L.L. Thatcher, Editors. 1960, US Government Printing Office. US. p. 1454-1458. 
13. Vijayabaskar, P., and S. T. Somasundaram, Isolation of bacteriocin producing lactic acid bacteria from fish gut and probiotic activity against common fresh water fish pathogen Aeromonas hydrophila. Biotechnology, 2008. 7(1): p. 124-128.

14. Aksoy, B.T., E. Bozkurt, and Ö.A. Sönmezoglu, Molecular detection of Bacillus cereus in milk by polymerase chain reaction. International Journal of Life Science and Biotechnology, 2021. 4(3): p. 389399.

15. Weisburg, W.G., et al., 16S Ribosomal DNA Amplification for phylogenetic study. Journal of Bacteriology, 1991. 173(2): p. 697-703.

16. Lorenz, T.C., Polymerase chain reaction: basic protocol plus troubleshooting and optimization strategies. Journal of Visualized Experiments, 2012. 63: e3998.

17. Veerakone, S., et al., First report of Tomato mosaic virus in Griselinia lucida, an epiphytic shrub native to New Zealand. Australasian Plant Disease Notes, 2010. 5(1): p. 107-109.

18. Chenna, R., et al., Multiple sequence alignment with the Clustal series of programs. Nucleic Acids Research, 2003. 31(13): p. 3497-3500.

19. Kumar, S., G. Stecher, and K. Tamura, MEGA7: molecular evolutionary genetics analysis version 7.0 for bigger datasets. Molecular Biology and Evolution, 2016. 33(7): p. 1870-1874.

20. El-Azizi, M., Novel microdilution method to assess double and triple antibiotic combination therapy in vitro. International Journal of Microbiology, 2016. 2016: e4612021.

21. Andrews, J.M., Determination of minimum inhibitory concentrations. Journal of Antimicrobial Chemotherapy, 2001. 48(1): p. 5-16.

22. Elshikh, M., et al., Resazurin-based 96-well plate microdilution method for the determination of minimum inhibitory concentration of biosurfactants. Biotechnology Letters, 2016. 38(6): p. 1015-1019.

23. Jain, S.N., et al., Antibiotic synergy test: Checkerboard method on multidrug resistant Pseudomonas aeruginosa. International Research Journal of Pharmacy, 2011. 2(12): p. 196-198.

24. Kerfeld, C.A., and K.M. Scott, Using BLAST to teach "E-value-tionary" concepts. PLoS Biology, 2011. 9(2): e1001014.

25. Wang, Y., Effect of probiotics on growth performance and digestive enzyme activity of the shrimp Penaeus vannamei. Aquaculture, 2007. 269(1-4): p. 259-264.

26. Onyuka, J.H.O., et al., Prevalence and Antimicrobial Susceptibility Patterns of Enteric Bacteria Isolated from Water and Fish in Lake Victoria Basin of Western Kenya. Interrnational Journal of Biomedical and Biological Engineering, 2011. 5(3): p. 131-138.

27. Park, K., et al., Enterotoxin genes, antibiotic susceptibility, and biofilm formation of low-temperaturetolerant Bacillus cereus isolated from green leaf lettuce in the cold chain. Foods, 2020. 9(3): p. 249.

28. Sukmarini, L., et al., Identification of antibiotic-resistance genes from lactic acid bacteria in Indonesian fermented foods. Hayati Journal of Biosciences 2014. 21(3): p. 144-150.

29. Cesur, S., and A. Demiröz, Antibiotics and the mechanisms of resistance to antibiotics. Medical Journal of Islamic World Academy of Sciences, 2013. 21(4): p. 138-142.

30. Soren, O., et al., Antimicrobial peptide novicidin synergizes with rifampin, ceftriaxone, and ceftazidime against antibiotic-resistant Enterobacteriaceae in vitro. Antimicrobial Agents and Chemotherapy, 2015. 59(10): p. 6233-6240.

31. Phillips, I., Clinical uses and control of rifampicin and clindamycin. Journal of Clinical Pathology, 1971. 24(5): p. 410.

32. Lahiri, N., et al., Rifampin resistance mutations are associated with broad chemical remodeling of Mycobacterium tuberculosis. Journal of Biological Chemistry, 2016. 291(27): p. 14248-14256.

33. Vogler, A.J., et al., Molecular analysis of rifampin resistance in Bacillus anthracis and Bacillus cereus. Antimicrobial Agents and Chemotherapy, 2002. 46(2): p. 511-513.

34. Dabbs, E.R., et al., Rifampicin inactivation by Bacillus species. The Journal of Antibiotics, 1995. 48(8): p. 815-819.

35. Hellweger, F.L., X. Ruan, and S. Sanchez., A simple model of tetracycline antibiotic resistance in the aquatic environment (with application to the Poudre River). International Journal of Environmental Research and Public Health, 2011. 8(2): p. 480-497. 
36. Shah, S.Q.A., et al., Prevalence of antibiotic resistance genes in the bacterial flora of integrated fish farming environments of Pakistan and Tanzania. Environmental Science \& Technology, 2012. 46(16): p. 8672-8679.

37. Saeed, B.M.S., B.A. Abbas, and S.A.N. Al-jadaan, Molecular Detection of Tetracycline Resistance Genes. Basrah Journal of Veterinary Research, 2018. 17(3): p. 223-234.

38. Weber, D.J., et al., In vitro susceptibility of Bacillus spp. to selected antimicrobial agents. Antimicrobial Agents and Chemotherapy, 1988. 32(5): p. 642-645.

39. Naas, H.T., et al., Bacillus cereus as an emerging public health concern in Libya: Isolation and antibiogram from food of animal origin. Libyan Journal of Medical Sciences, 2018. 2(2): p. 56.

40. Rahman, N.A., A. Akhter, and N.J. Urmi, Evaluation of resistance pattern of the multi-drug resistant (MDR) bacteria isolated from burn wounds. Stamford Journal of Microbiology, 2013. 3(1): p. 6-8.

41. Agwa, O.K., C.I. Uzoigwe, and E.C. Wokoma, Incidence and antibiotic sensitivity of Bacillus cereus isolated from ready to eat foods sold in some markets in Portharcourt, Rivers state, Nigeria. Asian Journal of Microbiology Biotechnology \& Environmental Sciences, 2012. 14(1): p. 13-18.

42. Manten, A., and J.I. Terra, The antagonism between penicillin and other antibiotics in relation to drug concentration. Chemotherapy, 1964. 8(1): p. 21-29.

43. Weeks, J.L., E.O. Mason, and C.J. Baker, Antagonism of ampicillin and chloramphenicol for meningeal isolates of group B streptococci. Antimicrobial Agents and Chemotherapy, 1981. 20(3): p. 281-285.

44. Cole, F.S., et al., Effect of ampicillin and chloramphenicol alone and in combination on ampicillinsusceptible and-resistant Haemophilus influenzae type B. Antimicrobial Agents and Chemotherapy, 1979. 15(3): p. 415-419. 